\title{
Evacuated Tube Solar Collector with Multifunctional Absorber Layers
}

\author{
Sarvenaz Sobhansarbandia ${ }^{\mathrm{a}}$, Patricia M. Martinez ${ }^{\mathrm{b}, \mathrm{c}}$, Alexios \\ Papadimitratos $^{\mathrm{c}}$, Anvar Zakhidove,d,e, Fatemeh Hassanipour ${ }^{\mathrm{a}, *}$ \\ ${ }^{a}$ University of Texas at Dallas, Department of Mechanical Engineering, \\ Richardson, TX 75080 \\ ${ }^{b}$ University of Texas at Dallas, Department of Chemistry, \\ Richardson, TX, 75080 \\ ${ }^{c}$ University of Texas at Dallas, Nanotech Institute, \\ Richardson, TX 75080 \\ ${ }^{d}$ University of Texas at Dallas, Department of Physics, \\ Richardson, TX, 75080 \\ ${ }^{e}$ Energy Efficiency Center, National University of Science and Technology, MISIS, \\ Moscow, Russia,119049
}

\begin{abstract}
Solar water heaters (SWHs) are a well-established renewable energy technology that have been widely adopted around the world. In this study we have significantly improved the Evacuated Tube solar Collectors (ETCs) by utilizing the "dry-drawable" Carbon Nanotube (CNT) sheet coatings to increase the solar energy absorption and Phase Change Materials (PCMs) to increase the heat accumulation for application in solar water heaters. The proposed solar collector utilizes a phase change material namely Octadecane paraffin, with melting temperatures of $28^{\circ} \mathrm{C}$ which is categorized as non-toxic with long-term chemical stability PCM. As PCMs particularly in powder form may not be effective by itself due to the poor heat transfer rate, low thermal diffusivity and thermal conductivity, by combining CNT layers with the high thermal diffusivity and thermal conductivity compare to phase change materials, we are able to overcome the shortcomings of PCMs and design an innovative and efficient solar water heater. With the current technology,
\end{abstract}

\footnotetext{
${ }^{*}$ Corresponding author

Email address: fatemeh@utdallas.edu (Fatemeh Hassanipour)

URL: http://www.utdallas.edu/ fatemeh (Fatemeh Hassanipour)
} 
we can provide a near ideal black body surface, absorbing a maximum of $98 \%$, between $600-1100 \mathrm{~nm}$, of solar light striking the surface, and providing additional spectral absorption which improves the performance of the solar heater. Applying CNT sheets in conjunction with PCM enables heat storage directly on the collector for a more constant output, even on a cloudy day and prolonged output of heat at night.

Keywords: Evacuated tube solar collectors, Solar water heater, Carbon nanotube, Phase change material

\section{Nomenclature}

$c_{p} \quad$ Specific heat of PCM $(k J / k g K)$

$H \quad$ Latent heat of fusion of PCM $(k J / k g)$

$T_{m} \quad$ Melting temperature of PCM $\left({ }^{\circ} \mathrm{C}\right)$

$\rho \quad$ Density of PCM $\left(\mathrm{kg} / \mathrm{m}^{3}\right)$

$G_{t} \quad$ Global radiation $\left(W / m^{2}\right)$

$T_{W} \quad$ Water Temperature in the Tank $\left({ }^{\circ} \mathrm{C}\right)$

\section{Introduction}

A number of systems have been developed to collect solar energy and convert it into an alternative form of energy, electricity, or to use the solar energy to perform work, such as in the case of a solar water heater. An important component of all these systems is the solar collector, which absorbs the solar radiation from the sun and transfers it to some transfer medium such as water, which delivers the heat as hot water to a house or to a heat storage unit (Papadimitratos et al., 2016; Sobhansarbandi and Atikol, 2015). Among different types of solar collectors, one example of an advanced and highly effective type of solar collector is an Evacuated Tube solar Collectors (ETCs).

Evacuated tube solar collectors are designed in such a way that heat loss to the environment is reduced. Heat loss due to convection cannot cross a vacuum, as it forms an efficient isolation mechanism to keep the heat inside the collector tubes. Since two flat sheets of glass are normally not strong enough to withstand a vacuum, the vacuum is rather created between two concentric 
tubes. Figure 1 shows a typical evacuated tube solar collector which has two concentric tubes of glass with a vacuum in between that admits heat from the sun and transfers it to the heat pipe. The concentric glass tubes in ETCs are half spherically closed on one side and fused together on the other side. In order to absorb the solar power, an environmentally friendly, highly selective absorber layer is provided on the external surface of the inner glass tube. The heat pipe is immersed inside of the inner tube and it transfers the absorbed heat to the manifold, which transfers the heat to a circulating water line. This design enables the evacuated tubes to have a maximum production, as they are optimized in geometry and performance.

Current selective absorbers are made of Aluminum-Nitride (Al-N) layers with solar absorption of $92 \%$, thus $8 \%$ of solar energy is lost due to reflectivity of the absorber material (WesTech; Apricus). In addition, selective coating requires careful control over the sputtering process (up to 12 sputtered layers for some designs), and thus the manufacturing costs are expensive. Such coating with high reflectivity is less efficient compared to a black body coating layer that has a high absorption amount of 98\% (Zhang et al., 2005). Current solar absorbers require a gas or electric booster heater to provide functionality at night, on cloudy days, or in general when incident solar energy is insufficient, which this adds to installation and maintenance costs. Our target is to improve the ETCs by a qualitatively new technical approach for the selective absorptive layer. There is great potential to utilize carbonbased materials for the selective solar absorption coating in order to reduce the maintenance cost and removing the need for booster unit.

In this paper a new concept of multifunctional absorber layer (Carbon Nanotube (CNT) sheets) with inner layers of heat accumulator (Phase Change Material (PCM) microspheres) is introduced. The main obstacles in the incorporation of carbon-based materials into the medium and high temperature solar heaters, have been the poor heat conductivity and stability of such materials (Kutuzov et al., 2013). In this study applying a dry-drawable carbon nanotubes as "Absorbent Layer" is suggested, and is further improved by birolling into its porous network functional layers of heat accumulation microspheres of PCM. This unique strategy enables heat storage directly on the evacuated tube solar collectors when sunlight is insufficient (night times and cloudy days).

Carbon nanotube thin films are widely used for converting solar radiation energy into other energy forms such as heat and electricity (solar cells) (Wei et al., 2007; Klinger et al., 2012). For the solar application in low tem- 
peratures, metal oxide sol-gels with carbon-nanotubes additives have been studied as a spectral selective solar absorber coating (with high absorptivity and low emissivity) (Katzen et al., 2005; Katumba et al., 2008; Mor et al., 2006).

Phase change materials (with melting temperature less than $50^{\circ} \mathrm{C}$ ) have been studied for solar storage systems either in a storage tank or directly on the flat plate collectors (Seeniraj and Narasimhan, 2008; Boy et al., 1987; Kürklü et al., 2002). Integration of phase change materials inside of the evacuated tube solar collectors have been studied in the previous work of the authors, which served as the motivation of current work, as it strongly supports the effective heat accumulation behavior of phase change materials (Papadimitratos et al., 2016). In non-solar applications, thermal and energy storage behavior of phase change materials by addition of expanded graphite and/or carbon nanotubes for their thermal conductivity enhancement has been widely investigated (Sarı and Karaipekli, 2007; Zhang and Fang, 2006; Wang et al., 2009; Shaikh et al., 2007).

To the best knowledge of the authors, there is no previous study on a nanocomposites based solar selective absorber layer containing carbon nanotubes sheets with filler of phase change materials. This novel absorber layer can be easily coated on the solar tubes and can provide scaffolding for additive materials. By applying the specific method of birolling (Lima et al., 2011), we were able to produce the composite with any degree of densification and guest additive concentration (up to 95\%). Thus, the investigation of the properties of this multi-functional nanocomposite solar absorber will have fundamental scientific impact as well as potential technological applications.

\section{CARBON NANOTUBE SHEETS (HEAT ABSORPTION)}

Carbon Nanotube sheets include an array of tube-shaped material, made of carbon, having a diameter measuring on the nanometer scale. CNT sheets have various structures, differing in length, thickness, type of helicity and number of layers. They are elastic and strong compared to other fiber materials which usually lack one or more of these properties. Due to the unique properties, carbon nanotube technology can be used for a wide range of applications, e.g., conductive and high-strength composites, energy storage and energy conversion devices, sensors, nanometer-sized semiconductor devices, probes and interconnects (Baughman et al., 2002).

Multi-Wall Nanotubes (MWNTs) comprise of an array of graphene sheet 
seamlessly wrapped into a cylinder, that are concentrically nested like rings of a tree trunk (Baughman et al., 2002). MWNTs have typically lower thermal conductivity compared to Single-Wall Nanotubes (SWNTs) due to overlap between individual nanotubes (Aliev et al., 2009; Kwon et al., 2004). Such deficiency can be overcome by using multiple sheets and densifying the structure using a variety of solvent, for improved electrical conductivity of CNT sheets.

In this work, high thermal conductivity of the Carbon Nanotube leads to a fast energy transfer to the PCM layers when embedded in the CNT sheets. In addition to being excellent blackbody absorbers, carbon nanotube sheets are a fast source of Joule heating (Dong et al., 2007; Kim et al., 2001). Such improvement would entirely eliminate the need for a separate gas or electric booster for water heating system, by incorporating electric heating directly into the solar collector. The dry synthesis of MWNT and drawing methods developed by our technology have proved to be very promising for large scale production of carbon nanotube sheets, as $1 \mathrm{~cm}$ length MWNT forest, typically produces 5-8 meters of drawn sheets.

\section{PHASE CHANGE MATERIALS (HEAT ACCUMULATION)}

Phase change materials are latent heat storage materials. The thermal energy transfer occurs when the material changes from solid to liquid, or liquid to solid phase. They store up to 514 times more heat per unit volume than sensible storage materials, while absorption and release of heat happen at a nearly constant temperature (Sharma et al., 2009). Examples of phasechange materials include water, salt hydrates, certain hydrocarbons, metal alloys and paraffin. Among these materials, paraffin is the most promising one for thermal management in industrial applications, e.g., heat pumps, solar engineering, and spacecraft thermal control applications (Hassanipour and Lage, 2009). Paraffin is the organic family of heavy hydrocarbons called alkanes, with the general chemical formula $C_{n} H_{2 n+2}$. Paraffin composites, in powder form, consist of tiny beads (1-200 $\mu \mathrm{m})$ which contain phase-change material inside a polymer shell. Shells are rigid, impermeable and typically less than one micro in thickness. The composites encapsulate a solid-liquid PCM in such a way that the liquid phase characteristic is not apparent and no liquid leaks are observed during or after the phase change process as shown in Figure 2.

Paraffin offer important advantages over other PCMs. They have large spec- 
trum of latent heats $(220 \sim 270 \mathrm{~kJ} / \mathrm{kg})$ and melting points $\left(5.5 \sim 80^{\circ} \mathrm{C}\right)$ depending on the length of the alkane chain (n). Another advantages of paraffin are: (1) physical properties (high density, small volume change and low vapor pressure), (2) chemical properties (long-term chemical stability, compatibility with materials of construction, no toxicity) and (3) their low cost and availability. When a temperature peak occurs, PCM absorbs the excessive energy by going through a phase transition and releasing the absorbed energy later or when the peak has passed. Before a solid can melt, it must absorb a sufficient amount of energy to overcome the binding forces which maintain the solid structure. This energy for complete melting is referred to the latent heat (heat of fusion) of the material and represents the difference in thermal energy levels between liquid and solid states. Of course, solidification of liquid requires the removal of this latent heat with the consequent restructuring of atoms into a more stable lattice. However, phase change material by itself may not be effective due to the poor heat transfer rate, low thermal diffusivity and thermal conductivity of PCMs in general. A separate heat transfer medium must be employed in between to transfer energy from the source to the PCM and from PCM to the load more efficiently. The type of the paraffin which is selected for this research activity is Octadecane paraffin $\mathrm{C}_{18} \mathrm{H}_{38}$ with melting point around $28^{\circ} \mathrm{C}$ and extremely stable by having less than $1 \%$ leakage when heated to $250^{\circ} \mathrm{C}$ (Microtek). The thermophysical properties of Octadecane paraffin can be seen in Table 2 .

\section{Experimental Setup}

Common solar water heaters use an Aluminum-Nitride or similar selective coating that gives off a distinctive blue color and having higher reflection compared to black body absorber coating. This means that some part of the light is being reflected of the surface and not all of the solar energy is being absorbed. Figure 1(a) shows the schematic of a standard tabletop vacuum tube from WesTech Solar Energy Inc.(WT-B58) and the specification of the tube is shown in Table 1 (WesTech). The experimental setup is divided into three sections, section-I evaluating the effectiveness of carbon nanotube sheets, section-II comparison of heating rate of different layers of CNT sheets on blue and clear tubes and finally, section-III the effect of phase change materials as heat accumulator. 


\subsection{Section-I: Evaluating the effectiveness of carbon natotube sheets}

In this study, spinnable MWNT forest was grown by Chemical Vapor Deposition (CVD) synthesis on a silicon wafer with $3 \mathrm{~nm}$ of Iron film (Zhang et al., 2005). The Fe film was deposited using an electron-beam evaporation process (CHA-50). The MWNT forest grew from a gas mixture of $\mathrm{He} / \mathrm{H}_{2}$ $(56 \%)$ and $\mathrm{He} / \mathrm{C}_{2} \mathrm{H}_{2}(5 \%)$ with a $3865 \mathrm{sccm}$ flow rate inside of a quartz rector, maintained at $1 \mathrm{~atm}$, and at temperatures between $710-750{ }^{\circ} \mathrm{C}$ for 4-10 minutes. The range of forest heights varied from 100-600 $\mu \mathrm{m}$ depending on the growth parameters and the diameter was $\sim 10 \mathrm{~nm}$ (Zhang et al., 2005). Figure 3 depicts an SEM image of a MWNT forest with height $\sim 300 \mu \mathrm{m}$.

The CNT sheets are drawn from the side of a vertical MWNT forest (Zhang et al., 2005), and laminated on to a sample tube as shown in Figure 4. The drawing process of CNT sheets with the use of a motor (Figure 4(c)) can be applied for large area applications, which can be used to automatically coat the 2 meter-long solar collector tubes.

To test the differences, a solar simulator from Newport Co. (class ABA, model \#94062A) with $1000 \mathrm{~W}$ xenon lamp, with typical output power of $100 \mathrm{~mW} / \mathrm{cm}^{2}$ and working distance $7.0 \pm 0.5$ in was used (Newport). Control samples were made of glass tube, and different sample configurations are tested with varying layers of carbon nanotubes to investigate the temperature rise and heat accumulation of the proposed coating stacked/birolled in various number of layers. Two sets of tests have been performed starting at room temperature, one with the undensified while the other set was with the densified layers of the carbon nanotubes. The nanotubes were densified by coating the nanotubes with ethanol and allowing to air dry, which improves the thermal conductivity of the nanotubes by removing the insulating air between the tubes and allowing more intimate contact between the individual nanotubes and the glass. This also improves the mechanical strength of the CNT sheet (Zhang et al., 2005).

Figure 5 shows the temperature rise of the tabletop testing of densified carbon nanotube sheets versus undensified layers of carbon nanotube sheets using the solar simulator. Control sample was the clear glass tube sample without any coating. This figure shows that the 15 layers of densified nanotubes had a better performance compared to 15 layers of undensified sheets. In general, the 15 layers of densified nanotubes worked the best. The graphs show great promise that the nanotube sheets provided additional spectral absorption and are able to improve the performance of the solar heater. 
Consequently, the densified layers of CNT sheets have been chosen for the experiment in the next section.

\subsection{Section-II: Comparison of heating rate of different layers of CNT sheets on blue and clear tubes}

In preparation for full scale testing, we used clear tubes that match the length and diameters of the tabletop units from WesTech shows in Table 1. The tubes were coated with the CNT material, which is fabricated by continuously spinning nanotube sheets by rotating the tube while translating the nanotube forests linearly along the tube length, as shown in Figure 6. Then the tubes were vacuum sealed with an outer tube, matching WesTech's specifications (WesTech) . The heat pipe which is attached into a small water tank of $600 \mathrm{ml}$ (with initial temperature of $25^{\circ} \mathrm{C}$ ), inserted into each tube individually. The water temperature in the tank $\left(T_{W}\right)$ are recorded during the time of the experiment, while the system settled into a steady condition.

The first configuration was made by applying 5, 10, 15 and 20 densified layers of nanotubes on the standard blue tube. The full scale system is placed in the field at the same time period in one sunny day of Texas, where the total global radiation $\left(G_{t}\right)$ on the surface of the collectors which is measured by the SP-Lite2 Pyranometer can reach $947 \mathrm{~W} / \mathrm{m}^{2}$ (Papadimitratos et al., 2016). The performance was compared with the control tube without any coating during the same time period. Figure 7 shows the variation of the number of densified layers of nanotubes on the blue tube. So far, 15 densified layers of nanotubes were demonstrated the effectiveness of the optimum number of layers of carbon nanotubes, so the same number of layers have been applied for the next configuration.

In the second configuration, the comparison between clear tube and blue tube with and without any coating have been investigated. A clear tube with 15 densified layers and a standard Al-N (blue) tube with 15 densified layers have been compared. Figure 8 shows that an Al-N (blue) tube with 15 densified layers of nanotubes have better performance compared to the clear tube. This demonstrated the improved optical absorption of the black nanotubes as an improvement upon existing technology, and confirmed the optimum number of layers of CNTs for the next experiment, where CNT have been used in conjunction with PCM. 


\subsection{Section-III: The effect of phase change materials as heat accumulator}

The evacuated solar tubes are coated with CNT sheets and Octadecane paraffin (selected phase change material) through the ionization coating system. The ionization deposition system works by creating an electrostatic field between negatively charged powders and positively charged MWNT sheet. This method allows to uniformly deposit powder PCM onto continuous MWNT sheets pulled from a forest. Figure $9(\mathrm{a})$ and (b) shows the schematics of the system. When pressurized air enters the ionization chamber, it becomes negatively charged due to the presence of an ionizer. This charged air is then passed to the powder chamber allowing the PCM to become ionized and attracted to the MWNT sheet which has been grounded from the forest substrate. By changing the ionization voltage, it is possible to control the amount of PCM deposited on the MWNT sheet. A vibrational motor is needed to overcome the agglomeration of the PCM powder while in the powder chamber and avoid the deposition of big clusters onto the MWNT sheets.

To see the effect of PCM addition on heat transfer rate, at first we measured the temperature for three solar tube samples: (1) 15 layers of CNT sheet only, (2) 15 layers of CNT sheet coating with $3 \mathrm{~g}$ of PCM, and (3) 15 layers of CNT sheet with $4.5 \mathrm{~g}$ of PCM, as shown in Figure 10. The small glass tube dimensions were $15 \mathrm{~cm}$ in length and $15 \mathrm{~mm}$ in diameter. The water was injected inside of the glass tubes, and the thermocouples are attached into the water in a way to measure the temperature of the water during the testing period. The test is conducted on a sunny day with outside temperature around $38^{\circ} \mathrm{C}$ with the maximum global radiation $\left(G_{t}\right)$ of $947 \mathrm{~W} / \mathrm{m}^{2}$ same as in Section-II (Papadimitratos et al., 2016). On a sunny day, the outdoor temperature is much higher than the Octadecane paraffin melting temperature, so it melts quickly and changes to liquid phase.

As it can be seen in Figure 10, the addition of phase change materials has improved the heat transfer rate compared to the other tube with no PCM. The PCM is fully melted very quickly, as the temperature reaches its melting point shortly. Based on the latent heat storage of the PCM, the total energy storage can be calculated as multiplying the mass by latent heat of the PCM for each tube, and it can be written as following:

$$
Q=m_{\text {Octadecane }} H_{\text {Octadecane }}
$$

where $\mathrm{m}$ is the mass of Octadecane in $\mathrm{kg}$, and $\mathrm{H}$ is the latent heat capacity 
of in $\mathrm{kJ} / \mathrm{kg}$. The total amount will be:

$$
Q_{\text {tube }(2)}=(0.003)(244 k J / k g)=0.732 k J=732 J
$$

$$
Q_{\text {tube(3) }}=(0.0045)(244 \mathrm{~kJ} / \mathrm{kg})=1.098 \mathrm{~kJ}=1098 \mathrm{~J}
$$

This value represents the energy storage capacity of sample tube(2) and (3) as they have different amount of PCM. Therefore the temperature of the water for tube(3) which has $4.5 \mathrm{~g}$ of PCM will remain higher compared to the other tubes due to the higher amount of latent heat storage of PCMs.

For the second configuration, we decided to repeat the test in a cooler day, when outdoor temperature is around the melting temperature of PCM around $32{ }^{\circ} \mathrm{C}$, for a longer period of time (about 7.5 hour). Also, to investigate the effect of PCM higher concentration (in CNT coating layer) on heat absorption, we repeated the test for an extra sample of solar tube coated with 15 layers of CNT sheets and $14 \mathrm{~g}$ of paraffin powder which is shown as tube(4) in Figure 11(a). Figure 11(b) shows that using PCM combined with carbon nanotube sheets leads to faster temperature rise even in a cloudy day, also the temperature remains constant around $50^{\circ} \mathrm{C}$. This is due to the melting process and high latent heat capacity of the paraffin. Figure 11 is showing a very interesting result that the small PCM concentration shows the water temperature around $43 \sim 45^{\circ} \mathrm{C}$, while the solar tube with $14 \mathrm{~g}$ of $\mathrm{PCM}$ increase the temperature to $50^{\circ} \mathrm{C}$ even on a cloudy windy day. The latent heat storage of the tube with $14 \mathrm{~g} \mathrm{PCM} \mathrm{(tube(4))} \mathrm{is} \mathrm{as} \mathrm{follows:}$

$$
Q_{\text {tube }(4)}=(0.014)(244 k J / k g)=3.416 k J=3416 J
$$

This latent heat energy, consequently result in a constant water temperature around $50{ }^{\circ} \mathrm{C}$ during the experiment, while the outside temperature was just a few degrees higher than the PCM melting temperature. The tube with higher concentration of PCM (tube(4)) has a longer delayed cooling period and keeps water in higher temperature compared with the other tubes. This results in improving the performance of the system during the evening or at night when solar radiation is not available and the demand side needs the hot water with the temperature around $40^{\circ} \mathrm{C}$.

Also, the absorption of densified CNT with and without PCM was investigated in order to understand the effect of PCM on the absorptivity of the coating. In this test, 5 layers of CNT sheets with and without $0.07 \mathrm{~g}$ of PCM are chosen. The sample is prepared by the method described above 
on top of a $1.5 \times 1.5 \mathrm{~cm}$ glass substrate. Using a Perkin Elmer Lambda 900 UV-VIS/NIR Spectrometer, reflectance (with an integrated sphere attachment) and transmittance measurements were recorded in order to calculate the absorption through $\mathrm{A}=1-(\mathrm{T}+\mathrm{R})$. From Figure 12 , it can be seen that the addition of PCM on the clear tube with 5 layers of CNT coating increases the absorption by $\sim 40 \%$ compared to the clear tube with 5 layers of CNT with no PCM. The Spectrum discontinuity presented in 5 layers with PCM at 860 $\mathrm{nm}$ is due to a crossover between the light source and the detector in the UV-VIS apparatus. These results show that the absorptivity can be further improved by additional CNT layers to the coating, as it can be seen that on the blue tube with 5 layers of CNT the absorption is linearized compared to the blue tube with no coating.

Carbon nanotube sheets exhibit very low reflection, 5 layers of undensified CNT achieve $<3 \%$ reflectance over the solar spectrum, further addition of layers marginally reduced the reflection, which saturated around 2\%. (Martinez et al., 2017). Moreover, the reflectivity of PCM increases negligibly when the PCM film thickness increases (Goia et al., 2012), thus, it is expected that the coating with $14 \mathrm{~g}$ of $\mathrm{PCM}$ have a similar reflection spectrum as the sample with $0.07 \mathrm{~g}$ of PCM.

It should be noted that when "CNT plus PCM" selective coating is used inside the vacuum evacuated tube collector (ETC), special care should be taken to avoid the overheating of this composite selective coating. This is naturally taken care of when ETC is loaded with cold water in an external heat exchanger, which keeps removing heat generated in ETC by constantly heating the external water. However, if the water in exchange is switched off for long time, the ETC works without a load and the overheating of $\mathrm{CNT}+\mathrm{PCM}$ may happen on a very sunny day, degrading the polymeric outer body of the microcapsule of PCM. For this reason, the higher temperature PCM and more robust microcapsules are recommended for practical longevity of ETC SWH.

\section{CONCLUSION}

In this project we have demonstrated the advantages of carbon nanotube sheets (CNT) multilayer coatings on evacuated solar tube collectors compared to the standard blue tubes in existing solar water heaters. With the addition of CNT sheets, we can provide a near ideal black body surface, absorbing a maximum of $98 \%$, between $600-1100 \mathrm{~nm}$, of solar light striking the 
surface. The temperature increase of the blue coating in standard commercial tubes versus carbon nanotube coatings were observed. The results are promising that the carbon nanotube sheets will provide additional spectral absorption improving the performance of the solar heater. We also combined CNT sheets with paraffin phase change material (PCM) which have high latent heat capacity and improved the performance of the evacuated solar tubes by increasing the heat accumulation. By applying PCM in solar water heaters, during the sunshine hours, the water gets heated up and its temperature remains around the constant value as a result of having the latent heat energy transferred from the PCM. During off sunshine hours, the PCM can delay the cooling rate of water by releasing stored latent heat energy, that can result in providing hot water to the demand side in cloudy days or when the solar radiation is insufficient.

It can be concluded that using an integrated evacuated tube with CNT sheet layers can increase the solar radiation absorption. Also applying the proper type of phase change material (that can be fully melted depending on whether the temperature reaches into its melting temperature) in conjunction with the CNT sheets can improve the solar water heater performance significantly by keeping the water at a uniform high temperature for a longer period of time during the day. Furthermore, the overheating of SWH should be avoided though to protect PCM of thermal degradation.

\section{Acknowledgement}

This work was supported by the U.S. Department of Energy (DOE) under the STTR award number DE-SC0009447 and Welch Foundation grant AT 16-17. The authors would like to thank the WesTech Solar Energy Inc. and Apricus Solar Co. for the donation of the evacuated tube solar collectors. Also, the authors would like to thank Mr. Mick Humphreys for useful discussions. Partial financial support from the Ministry of Education and Science of the Russian Federation in the framework of Increase Competitiveness Program of NUST-MISiS (No.K2-2015-014) is also appreciated. 
365 List of Tables

3661 Specification of Evacuated Tube Solar Collector (Apricus; WesT-

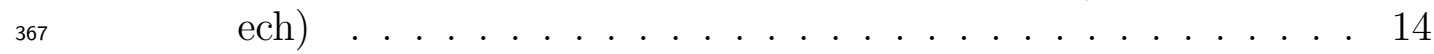

3682 Thermophysical properties of Octadecane (Himran et al., 1994;

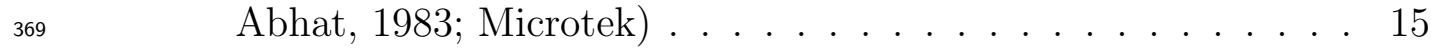


Table 1: Specification of Evacuated Tube Solar Collector (Apricus; WesTech)

\begin{tabular}{|l|c|c|}
\hline Properties & WesTech Solar Energy Inc. & Apricus Solar Co. \\
\hline Length of Glass Tube $(\mathrm{mm})$ & $513 \pm 5$ & $513 \pm 5$ \\
\hline Outer Tube Diameter $(\mathrm{mm})$ & 58 & 57.912 \\
\hline Inner Tube Diameter $(\mathrm{mm})$ & 47 & 46.99 \\
\hline Glass Thickness $(\mathrm{mm})$ & $1.6-2$ & 1.8 \\
\hline Glass Material & Borosilicate Glass 3.3 & Borosilicate Glass 3.3 \\
\hline Absorptive Coating Material & ALN/AlN-SS/CU & Cu-Al/N-SS \\
\hline Absorptance & $>92 \%$ & $>93 \%$ \\
\hline Emittance & $<8 \%$ & $<8 \%$ \\
\hline Vacuum (Pa) & $P<5 \times 10^{-3}$ & $P<5 \times 10^{-3}$ \\
\hline
\end{tabular}


Table 2: Thermophysical properties of Octadecane (Himran et al., 1994; Abhat, 1983; Microtek)

\begin{tabular}{|l|c|}
\hline Properties & Octadecane \\
\hline Chemical Formula & $C_{18} H_{38}$ \\
\hline$T_{m}\left({ }^{\circ} \mathrm{C}\right)$ & 28.1 \\
\hline$H(k J / k g)$ & 244 \\
\hline$c_{p}$-liquid $(k J / k g K)$ & 0.56 \\
\hline$c_{p}$-solid $(k J / k g K)$ & 0.48 \\
\hline$\rho$-liquid $\left(k g / m^{3}\right)$ & 774 \\
\hline$\rho$-solid $\left(k g / m^{3}\right)$ & 814 \\
\hline Thermal Conductivity-liquid $(\mathrm{W} / \mathrm{mK})$ & 0.148 \\
\hline Thermal Conductivity-solid $(\mathrm{W} / \mathrm{mK})$ & 0.15 \\
\hline Thermal Stability & Extremely stable-Less than $1 \%$ leakage $@ 250{ }^{\circ} \mathrm{C}$ \\
\hline
\end{tabular}




\section{List of Figures}

1 Schematic of evacuated tube from:(a) WesTech Solar Energy Inc. (WesTech) (b) Apricus Solar Co. (Apricus; Papadimitratos et al., 2016) . . . . . . . . . . . . . . . . . . . 17

2 Encapsulate solid-liquid PCMs . . . . . . . . . . . 18

3 SEM image of a $300 \mathrm{~m}$ MWNT forest . . . . . . . . . . . . 19

4 The dry drawing of carbon nanotube (CNT) sheets: (a) from CVD grown CNT forest (Zhang et al., 2005), (b) sheet being drawn from vertical forest (Zhang et al., 2005), (c) motorized setup of CNT sheet drawing of CNT forest grown . . . . . . . 20

5 Comparison of varying layers of undensified and densified nanotubes sheets on glass tube (clear tube) . . . . . . . . . . . 21

6 Fabrication of the tubes by continuously spinning nanotube sheets around the rotating tubes (a) Coating a clear glass tube with 15 layers of carbon nanotube sheets as a sample (b) Comparison of the coated tubes with with varying layers of nanotubes. From right to left: Blue Tube +5 layers of nanotubes, Clear Tube +15 layers of nanotubes, Blue Tube +15 layers of nanotubes, Blue Tube +20 layers of nanotube .22

7 The comparison of heating rate of blue tube with varying layers of nanotubes . . . . . . . . . . . . . . . . 23

8 The comparison of heating rate of the industrial standard tubes versus coating with nanotubes . . . . . . . . . . . . 24

9 (a) Schematics of the ionization chamber used to deposit PCM onto MWNT sheets. (b) Left: Image of the ionization machine, Right: MWNT sheet being coated with a PCM material 25

10 (a) Installment of the 3 system samples, (b) Temperature of three solar tube samples: (1) CNT sheet only (2) CNT sheet coating with $3 \mathrm{~g}$ of PCM, and (3) CNT sheet with $4.5 \mathrm{~g}$ of PCM 26

11 (a) Installment of the 4 system samples, (b) Temperature comparison for 4 sample systems . . . . . . . . . . . . . . 27

12 Absorptivity versus wavelength for 5 different samples . . . . . 28 
Figure 1: Schematic of evacuated tube from:(a) WesTech Solar Energy Inc. (WesTech) (b) Apricus Solar Co. (Apricus; Papadimitratos et al., 2016) 


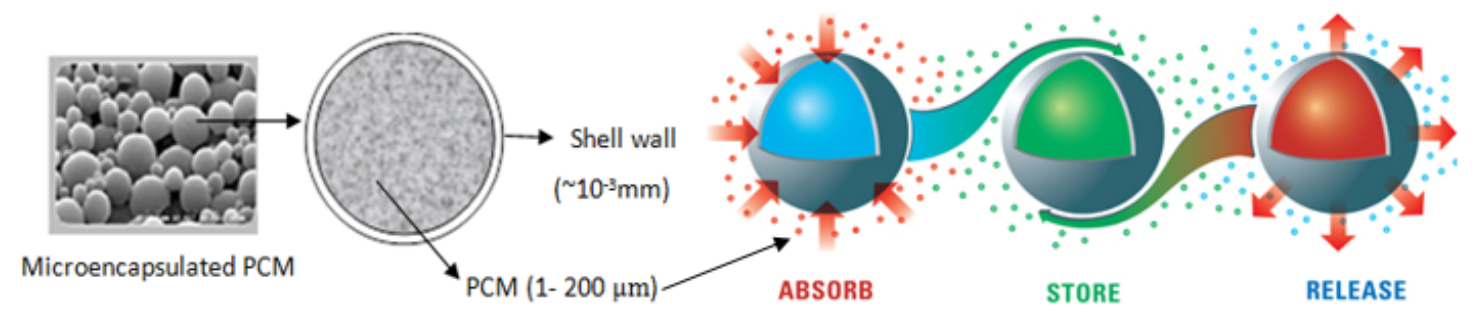

Figure 2: Encapsulate solid-liquid PCMs 


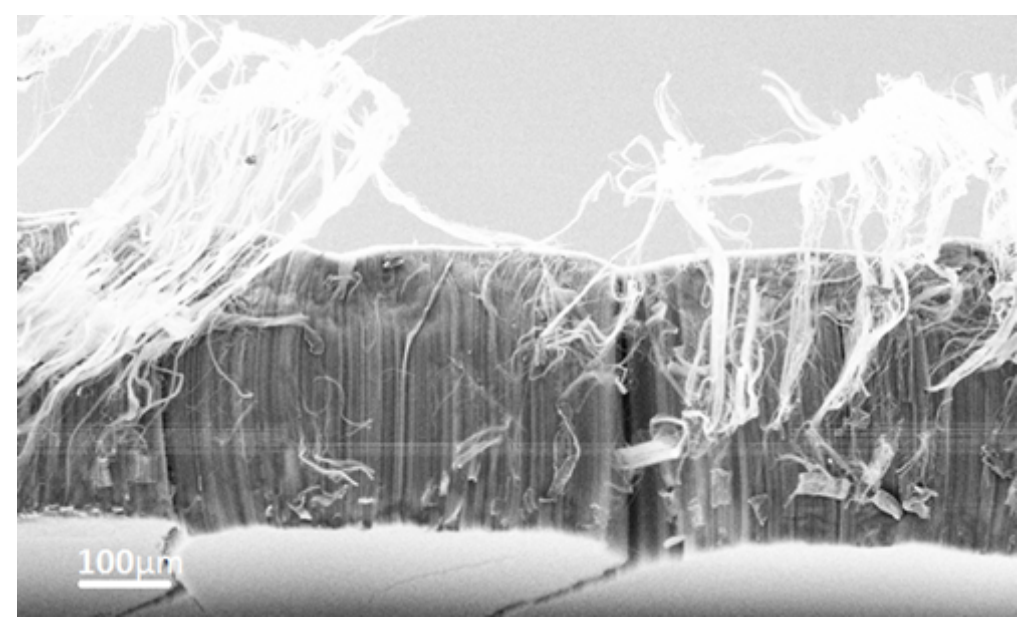

Figure 3: SEM image of a $300 \mathrm{~m}$ MWNT forest 


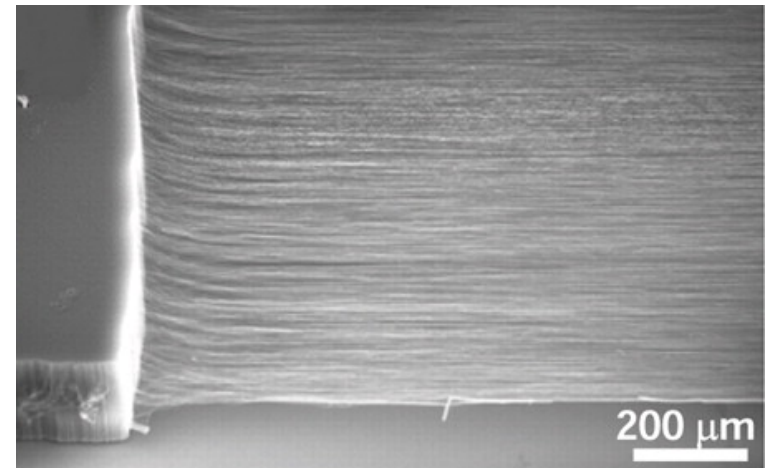

(a)

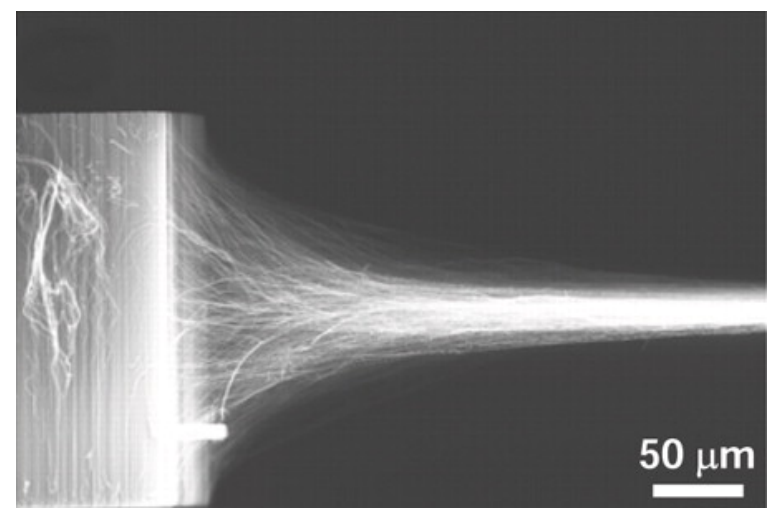

(b)

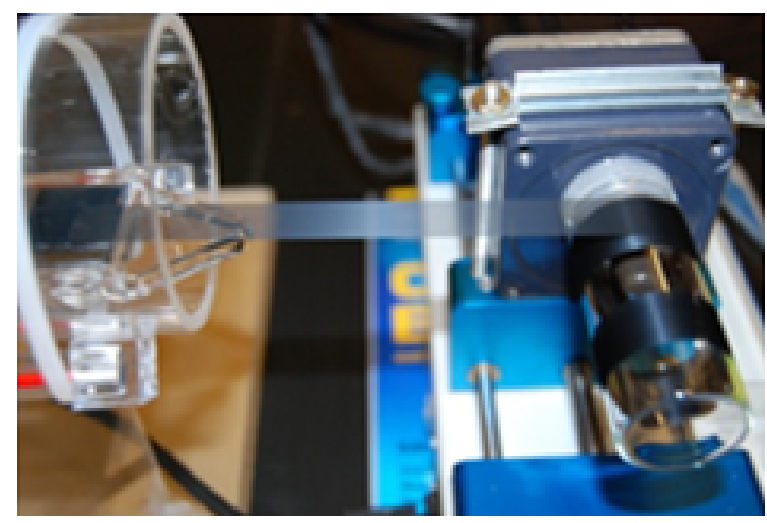

(c)

Figure 4: The dry drawing of carbon nanotube (CNT) sheets: (a) from CVD grown CNT forest (Zhang et al., 2005), (b) sheet being drawn from vertical forest (Zhang et al., 2005), (c) motorized setup of CNT sheet drawing of CNT forest grown 
Figure 5: Comparison of varying layers of undensified and densified nanotubes sheets on glass tube (clear tube) 
Figure 6: Fabrication of the tubes by continuously spinning nanotube sheets around the rotating tubes (a) Coating a clear glass tube with 15 layers of carbon nanotube sheets as a sample (b) Comparison of the coated tubes with with varying layers of nanotubes. From right to left: Blue Tube +5 layers of nanotubes, Clear Tube +15 layers of nanotubes, Blue Tube +15 layers of nanotubes, Blue Tube +20 layers of nanotube 


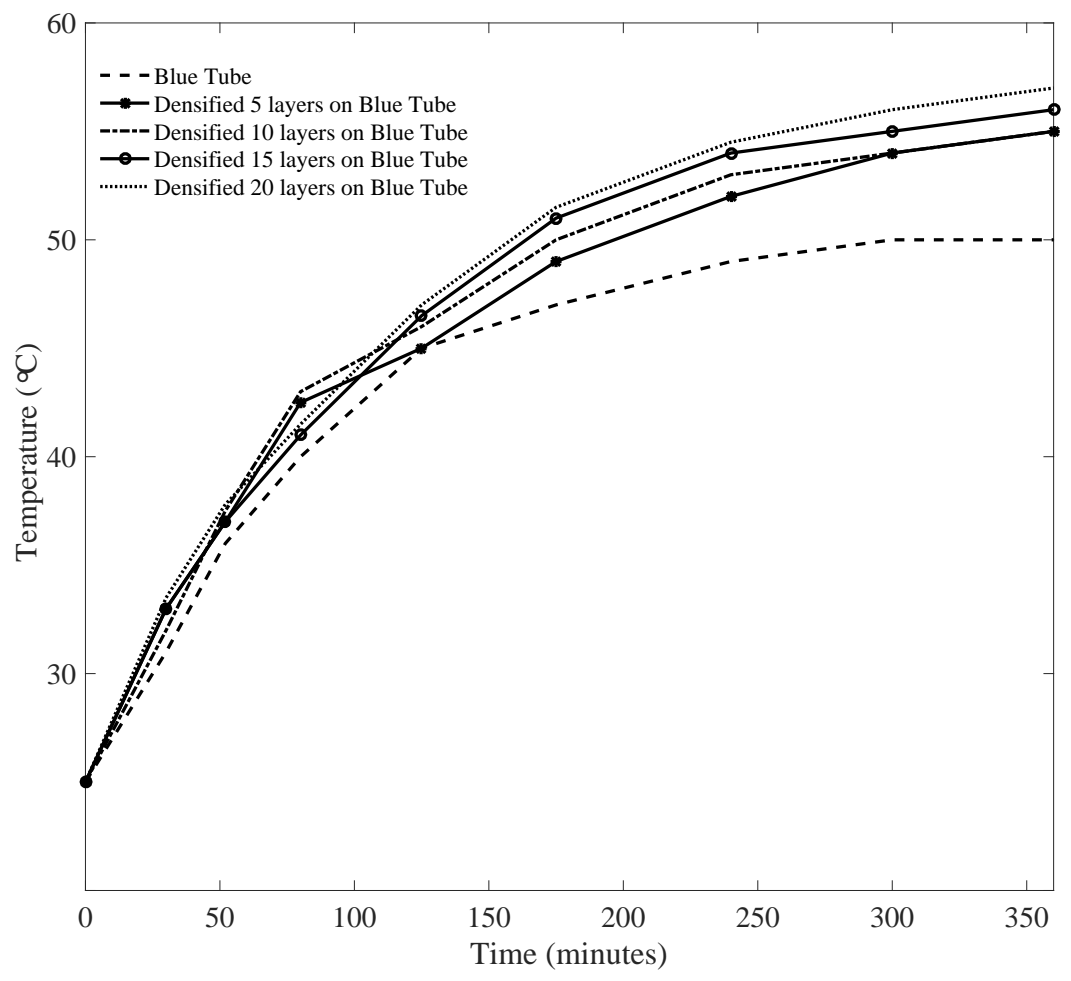

Figure 7: The comparison of heating rate of blue tube with varying layers of nanotubes 


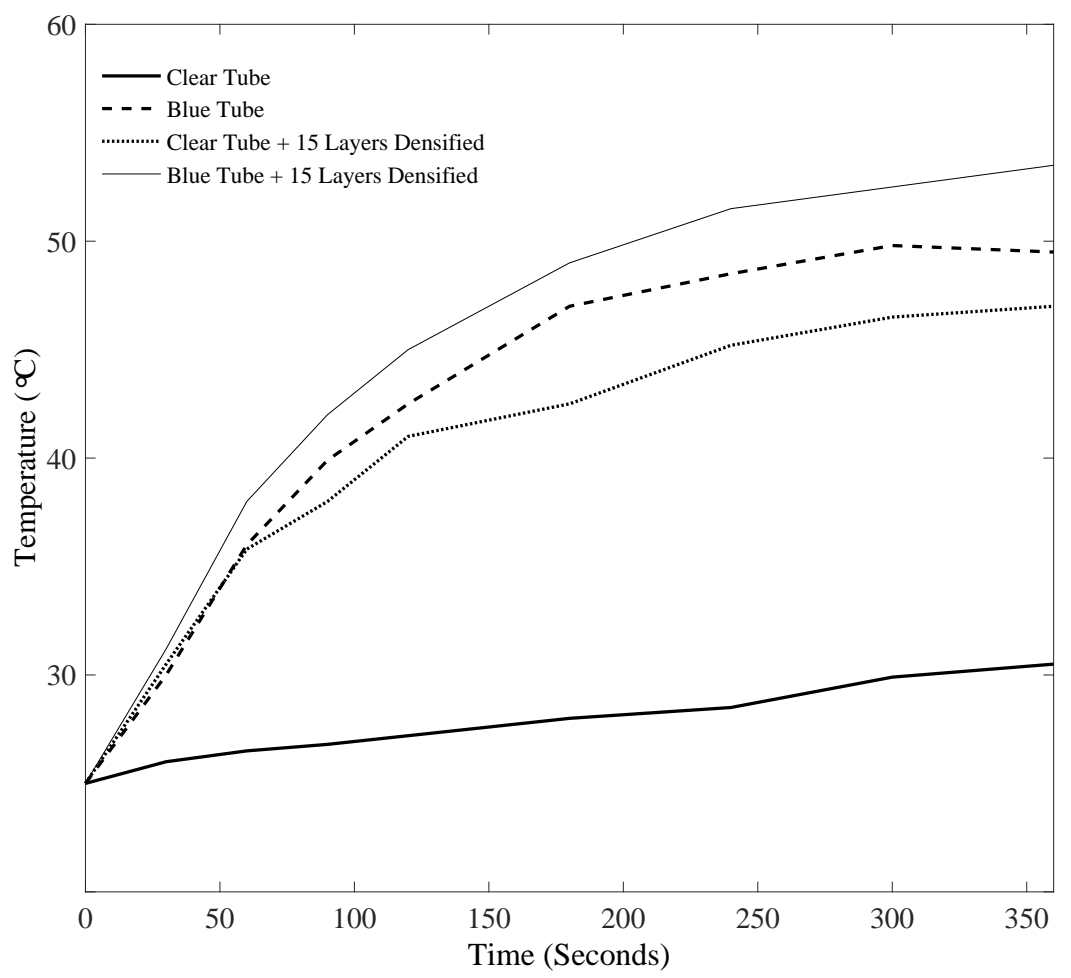

Figure 8: The comparison of heating rate of the industrial standard tubes versus coating with nanotubes 


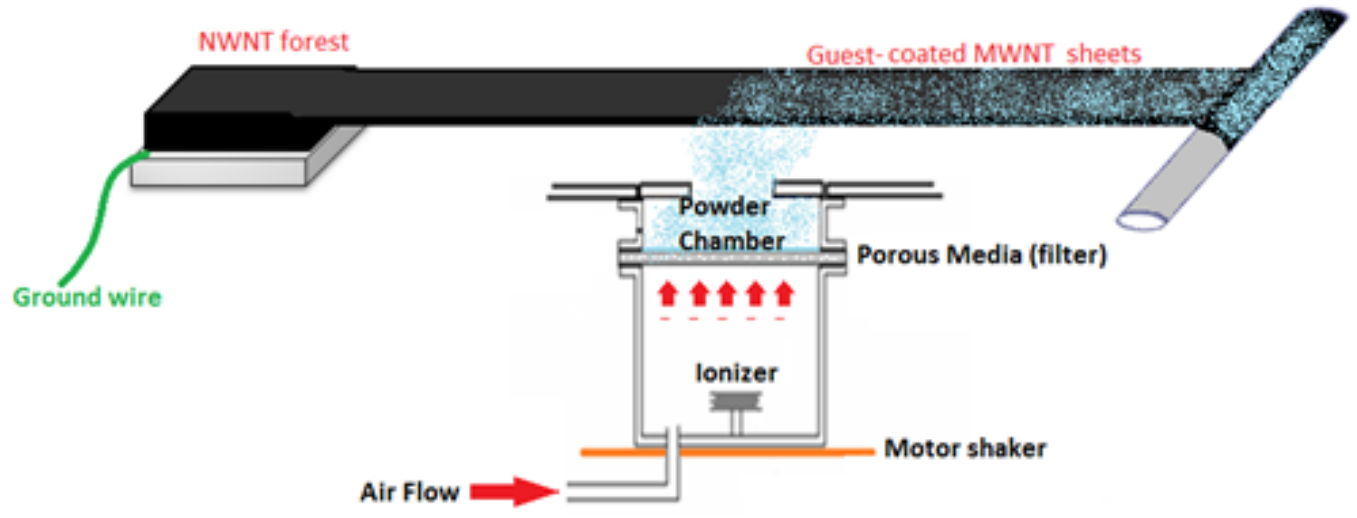

(a)
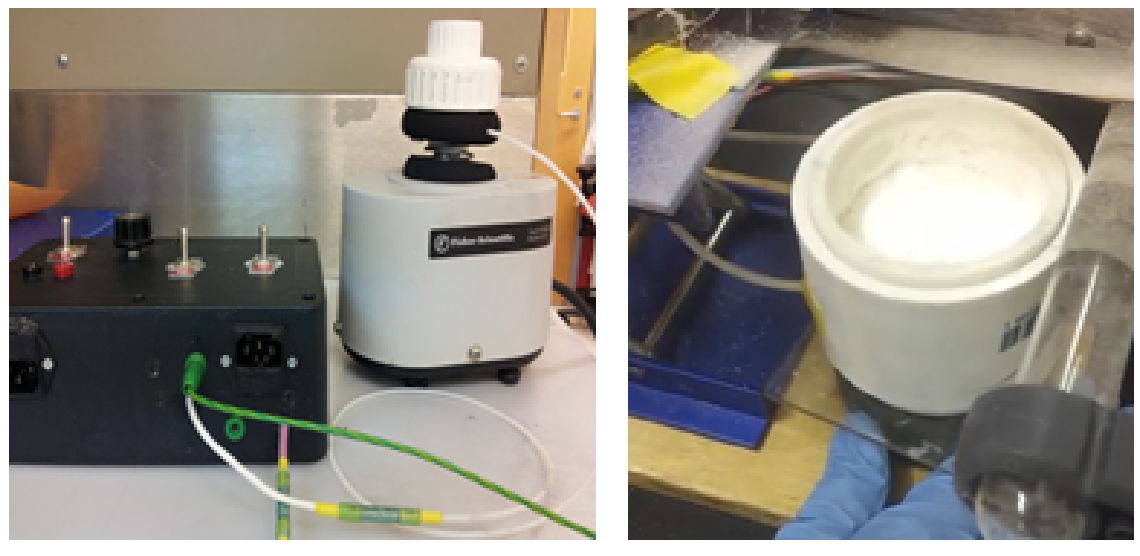

(b)

Figure 9: (a) Schematics of the ionization chamber used to deposit PCM onto MWNT sheets. (b) Left: Image of the ionization machine, Right: MWNT sheet being coated with a PCM material 


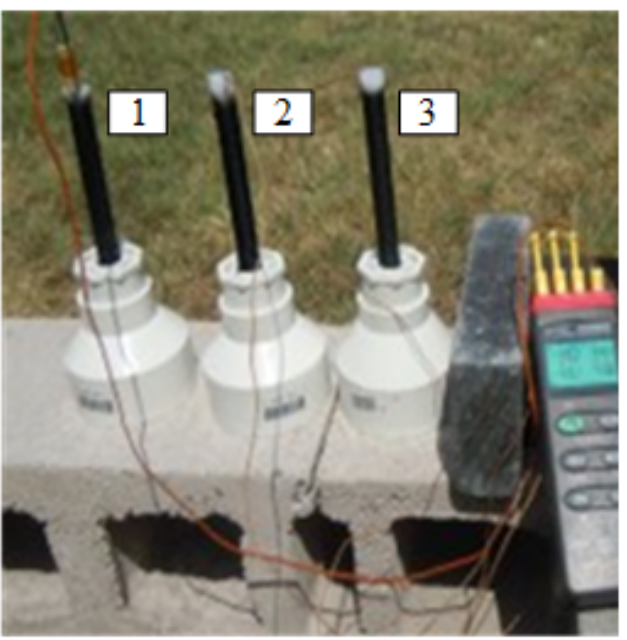

(a)

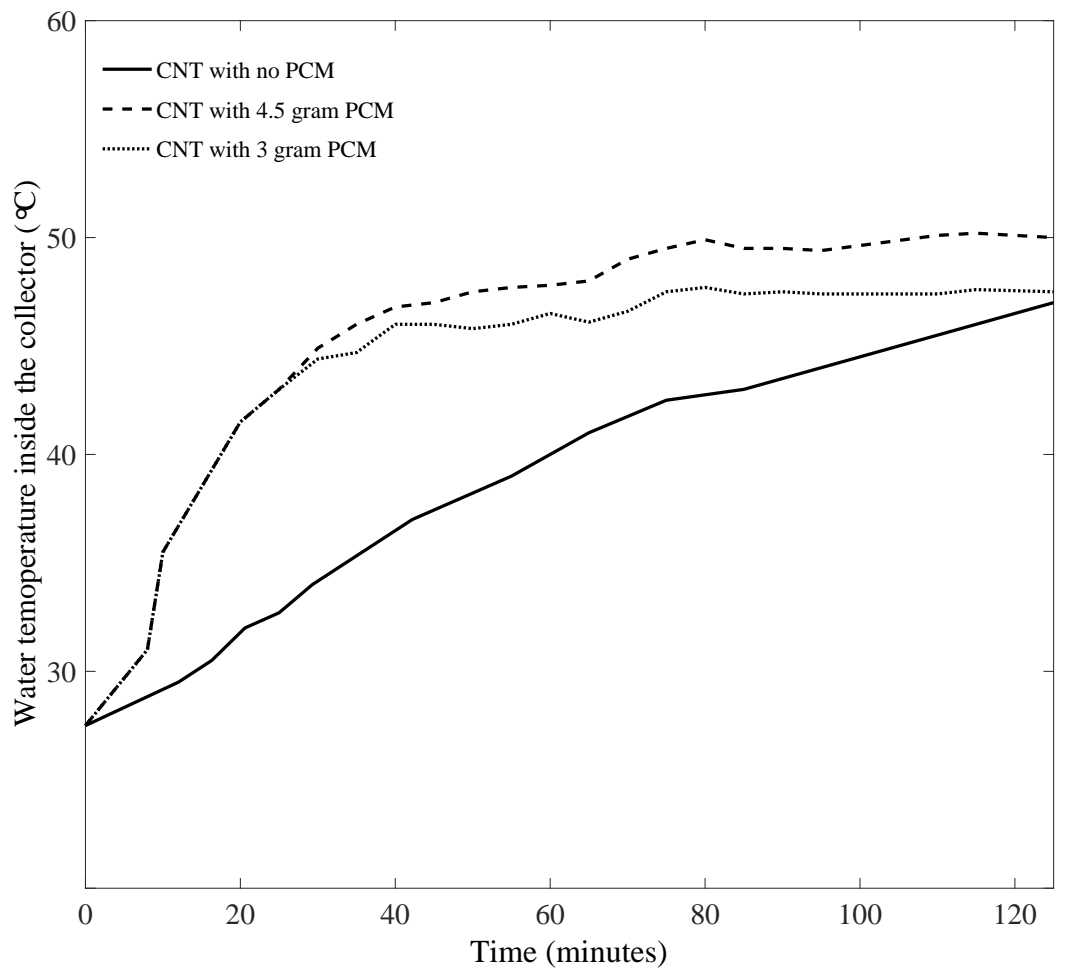

(b)

Figure 10: (a) Installment of the 3 system samples, (b) Temperature of three solar tube samples: (1) CNT sheet only (2) CNT sheet coating with $3 \mathrm{~g}$ of PCM, and (3) CNT sheet with $4.5 \mathrm{~g}$ of $\mathrm{PCM}$ 
Figure 11: (a) Installment of the 4 system samples, (b) Temperature comparison for 4 sample systems

(a)

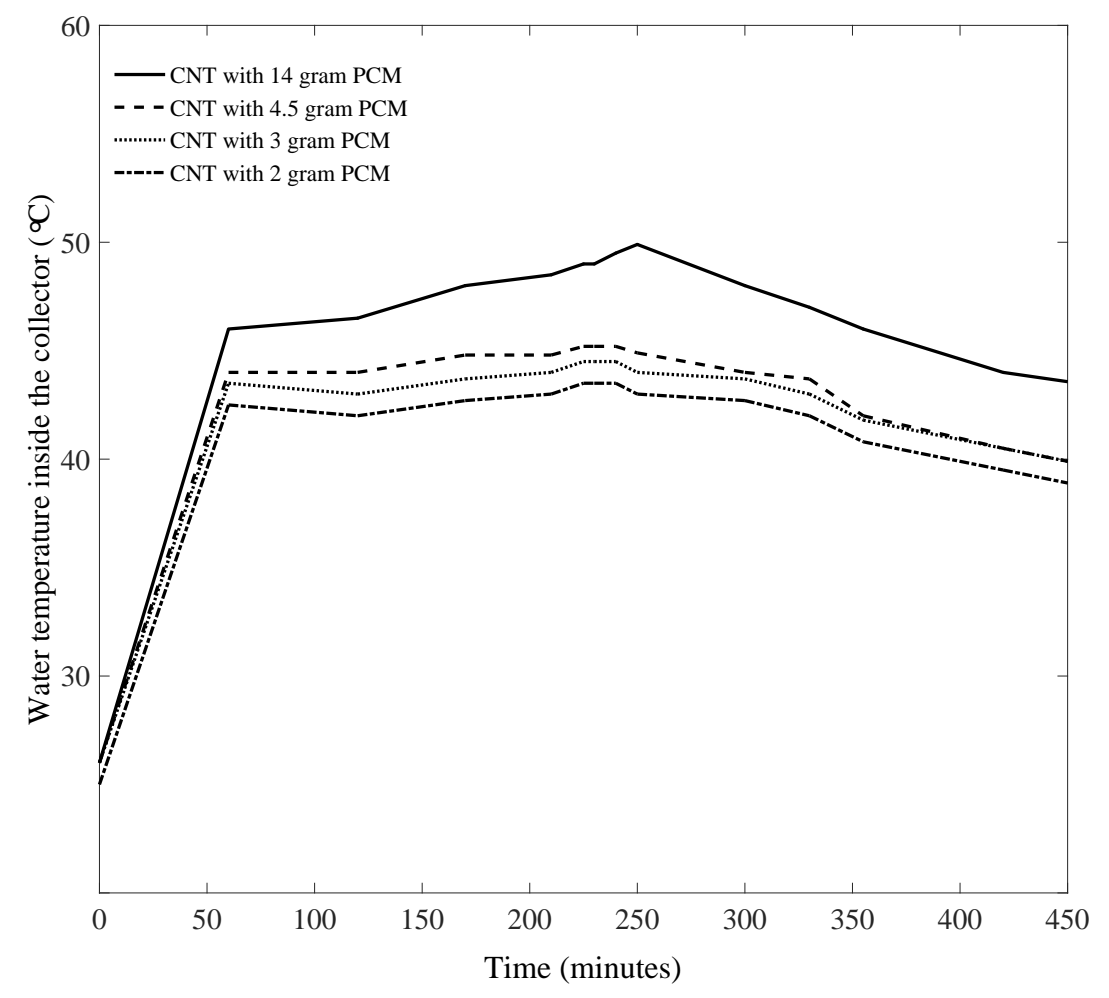

(b)

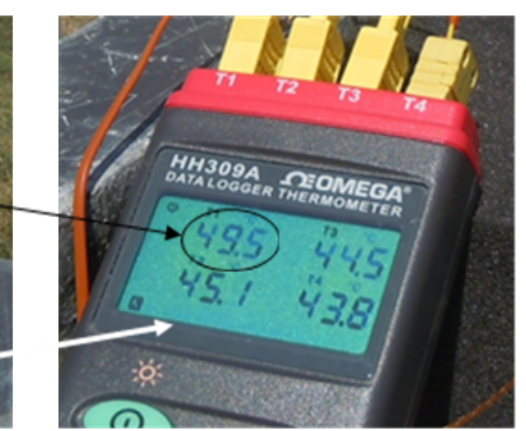




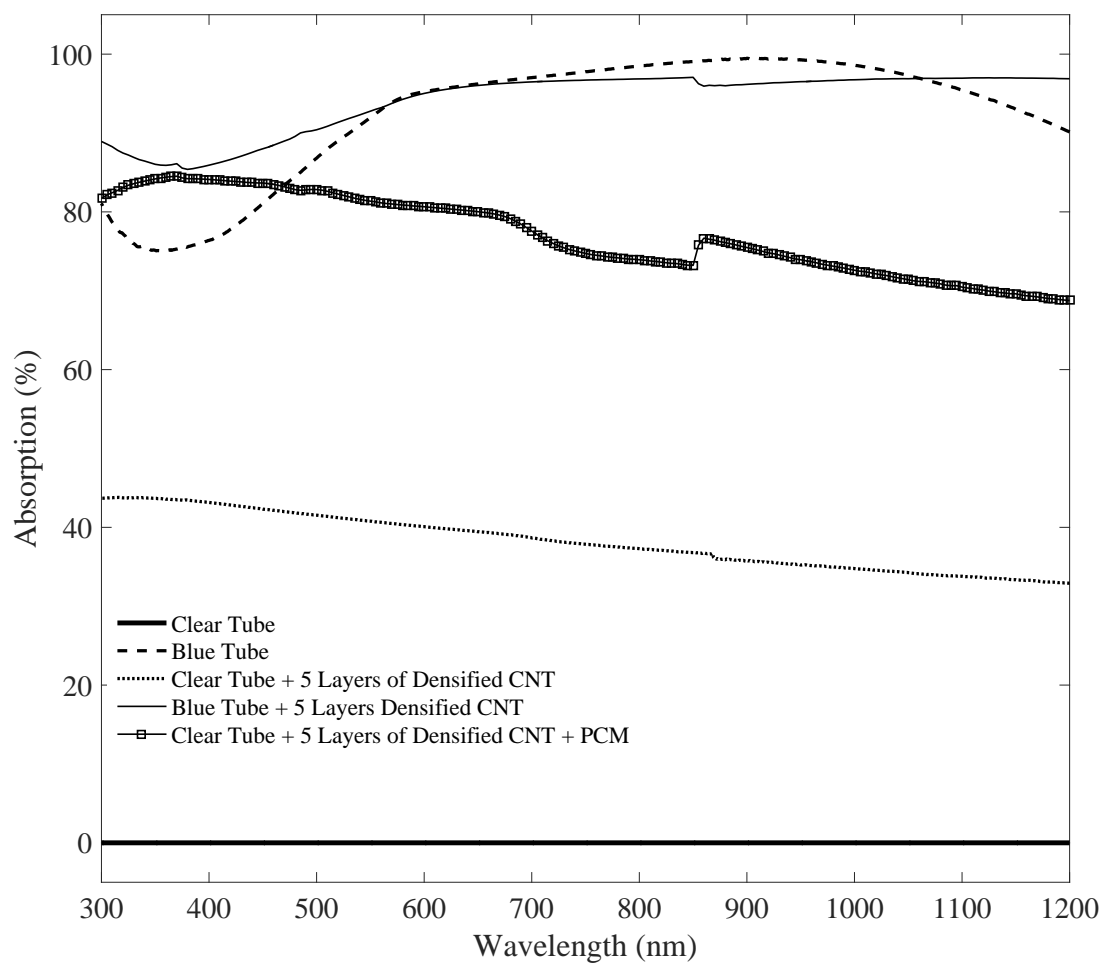

Figure 12: Absorptivity versus wavelength for 5 different samples 


\section{References}

Abhat, A., 1983. Low temperature latent heat thermal energy storage: heat storage materials. Solar energy 30, 313-332.

Aliev, A.E., Lima, M.H., Silverman, E.M., Baughman, R.H., 2009. Thermal conductivity of multi-walled carbon nanotube sheets: radiation losses and quenching of phonon modes. Nanotechnology 21, 035709.

Apricus, . Evacuated Tube Solar Collector. Technical Report.

Baughman, R.H., Zakhidov, A.A., de Heer, W.A., 2002. Carbon nanotubesthe route toward applications. Science 297, 787-792.

Boy, E., Boss, R., Lutz, M., 1987. A collector storage module-with integrated phase change material. Proc. ISES, Pergamon Press, Hamburg , 36723680 .

Dong, L., Youkey, S., Bush, J., Jiao, J., Dubin, V.M., Chebiam, R.V., 2007. Effects of local joule heating on the reduction of contact resistance between carbon nanotubes and metal electrodes. Journal of applied physics 101, 024320 .

Hassanipour, F., Lage, J.L., 2009. Numerical simulation of capillary convection with encapsulated phase-change particles. Numerical Heat Transfer, Part A: Applications 55, 893-905.

Himran, S., Suwono, A., Mansoori, G.A., 1994. Characterization of alkanes and paraffin waxes for application as phase change energy storage medium. Energy Sources 16, 117-128.

Katumba, G., Olumekor, L., Forbes, A., Makiwa, G., Mwakikunga, B., Lu, J., Wäckelgård, E., 2008. Optical, thermal and structural characteristics of carbon nanoparticles embedded in zno and nio as selective solar absorbers. Solar energy materials and solar cells 92, 1285-1292.

Katzen, D., Levy, E., Mastai, Y., 2005. Thin films of silica-carbon nanocomposites for selective solar absorbers. Applied surface science 248, 514-517.

Kim, P., Shi, L., Majumdar, A., McEuen, P., 2001. Thermal transport measurements of individual multiwalled nanotubes. Physical review letters 87, 215502. 
Klinger, C., Patel, Y., Postma, H.W.C., 2012. Carbon nanotube solar cells. PloS one 7, e37806.

Kürklü, A., Özmerzi, A., Bilgin, S., 2002. Thermal performance of a waterphase change material solar collector. Renewable Energy 26, 391-399.

Kutuzov, S., Vasil'chenko, G., Chirka, T., Panov, E., 2013. Thermal conductivity of carbon-based materials. Refractories \& Industrial Ceramics 54 .

Kwon, Y.K., Berber, S., Tománek, D., 2004. Thermal contraction of carbon fullerenes and nanotubes. Physical review letters 92, 015901.

Lima, M.D., Fang, S., Lepró, X., Lewis, C., Ovalle-Robles, R., CarreteroGonzález, J., Castillo-Martínez, E., Kozlov, M.E., Oh, J., Rawat, N., et al., 2011. Biscrolling nanotube sheets and functional guests into yarns. Science $331,51-55$.

Microtek, . Microencapsulated Phase Change Material. Technical Report. URL: http://www.microteklabs. com/data-sheets.html.

Mor, G.K., Varghese, O.K., Paulose, M., Shankar, K., Grimes, C.A., 2006. A review on highly ordered, vertically oriented tio 2 nanotube arrays: fabrication, material properties, and solar energy applications. Solar Energy Materials and Solar Cells 90, 2011-2075.

Newport, . Sol2A Class ABA Solar Simulators. Technical Report.

Papadimitratos, A., Sobhansarbandi, S., Pozdin, V., Zakhidov, A., Hassanipour, F., 2016. Evacuated tube solar collectors integrated with phase change materials. Solar Energy 129, 10-19.

Sarı, A., Karaipekli, A., 2007. Thermal conductivity and latent heat thermal energy storage characteristics of paraffin/expanded graphite composite as phase change material. Applied Thermal Engineering 27, 1271-1277.

Seeniraj, R., Narasimhan, N.L., 2008. Performance enhancement of a solar dynamic lhts module having both fins and multiple pcms. Solar Energy $82,535-542$.

Shaikh, S., Li, L., Lafdi, K., Huie, J., 2007. Thermal conductivity of an aligned carbon nanotube array. Carbon 45, 2608-2613. 
Sharma, A., Tyagi, V., Chen, C., Buddhi, D., 2009. Review on thermal energy storage with phase change materials and applications. Renewable and Sustainable energy reviews 13, 318-345.

Sobhansarbandi, S., Atikol, U., 2015. Performance of flat-plate and compound parabolic concentrating solar collectors in underfloor heating systems. Journal of Solar Energy Engineering 137, 034501.

Wang, J., Xie, H., Xin, Z., 2009. Thermal properties of paraffin based composites containing multi-walled carbon nanotubes. Thermochimica Acta 488, 39-42.

Wei, J., Jia, Y., Shu, Q., Gu, Z., Wang, K., Zhuang, D., Zhang, G., Wang, Z., Luo, J., Cao, A., et al., 2007. Double-walled carbon nanotube solar cells. Nano letters 7, 2317-2321.

WesTech, . Evacuated Tube Solar Collector. Technical Report.

Zhang, M., Fang, S., Zakhidov, A.A., Lee, S.B., Aliev, A.E., Williams, C.D., Atkinson, K.R., Baughman, R.H., 2005. Strong, transparent, multifunctional, carbon nanotube sheets. Science 309, 1215-1219.

Zhang, Z., Fang, X., 2006. Study on paraffin/expanded graphite composite phase change thermal energy storage material. Energy Conversion and Management 47, 303-310. 